МНОГОЛЕТНЯЯ ДИНАМИКА ЗАПАСОВ ВОДЫ В СНЕЖНОМ ПОКРОВЕ ЛЕСНОГО МАССИВА РЯЗАНСКОЙ МЕЩЕРЫ

DOI: $10.31618 /$ ESU.2413-9335.2020.5.73.684

Евсенкин Константин Николаевич

кандидат технических наук,

ФГБНУ «ВНИИГиМ им. А.Н. Костякова», г. Рязань

Ильинский Андрей Валерьевич

кандидат $\mathrm{c}$ х наук, доиент,

ФГБНУ «ВНИИГиМ им. А.Н. Костякова», г. Рязань

\title{
LONG-TERM DYNAMICS OF WATER RESERVES IN THE SNOW COVER OF THE RYAZAN MESCHERA FOREST AREA
}

\author{
Evsenkin Konstantin \\ candidate of technical Sciences \\ Federal State Scientific Institution \\ «All-Russian research institute for hydraulic engineering \\ and reclamation of $A . N$. Kostyakov», \\ Ryazan \\ Ilinskiy Andrey \\ candidate of agricultural sciences, associate professor \\ Federal State Scientific Institution \\ "All-Russian research institute for hydraulic engineering \\ and reclamation of $A$.N. Kostyakov», \\ Ryazan
}

\section{АННОТАЦИЯ}

В статье представлены результаты изучения многолетней динамики запасов воды в снежном покрове лесного массива близ п. Солотча. Также представлен анализ высоты и плотности снежного покрова. На основании результатов многолетних натурных исследований дана сравнительная оценка запасов воды в снежном покрове лесного массива. Установлено, что зимний период 2019-2020 гг. имел наименьшие запасы воды в снежном покрове: 31,5 мм, против среднемноголетних значений (84,0 мм).

\section{ABSTRACT}

The article presents the results of studying the long-term dynamics of water reserves in the snow cover of the forest near the village of Solotcha. The analysis of the height and density of snow cover is also presented. Based on the results of long-term field research, a comparative assessment of water reserves in the snow cover of the forest is given. It was found that the winter period of 2019-2020 had the smallest water reserves in the snow cover: $31,5 \mathrm{~mm}$, against the average annual values $(84,0 \mathrm{~mm})$.

Ключевые слова: атмосферные осадки, запас воды, мелиорированные земли, продуктивность, сельское хозяйство, снежный покров, экологическая безопасность.

Keywords: precipitation, water supply, reclaimed land, productivity, agriculture, snow cover, environmental safety.

В Нечерноземной зоне России снежный покров оказывает большое влияние на формирование водных режимов осушаемых земель. Содержание воды в атмосфере и наличие водных пространств во многом определяют погоду и климат на нашей планете, а также оказывают значительное влияние на формирование местных климатических условий $[1,2,7,8]$. Для обеспечения высокой продуктивности сельскохозяйственных культур необходима свежая вода, за счет которой на протяжении всего вегетационного периода поддерживается оптимальная влажность почвы [13, 14]. Распределение снежного покрова на водосборе и типах рельефа зависит от ряда постоянно действующих как природных, так и антропогенных факторов [11]. Значения мощности и плотности снежного покрова являются ключевыми параметрами в определении запаса воды в снеге [3, 12].

C целью изучения многолетней динамики изменения запасов воды в снежном покрове в феврале 2020 года были продолжены снегомерные наблюдения на землях лесного массива п. Солотча. Ранее проведенные исследования показали, что лесной массив п. Солотча способствует уменьшению скорости ветровых потоков оказывая благоприятное влияние на мощность снежного покрова $[4,6,9]$.

Снегомерная съемка на стационарном участке лесного массива п. Солотча выполнена по общепринятой методике [10]. Натурные исследования включают в себя определение плотности и высоты снежного покрова с использованием весового снегомера и переносной снегомерной рейки $[3,10,12]$. Снегомерные наблюдения на полевых участках были выполнены по промерной линии в форме равностороннего треугольника, общая длина маршрута 1 км в момент наибольшей высоты снежного покрова: 
перед началом весеннего таяния снега (конец февраля - начало марта) [12].

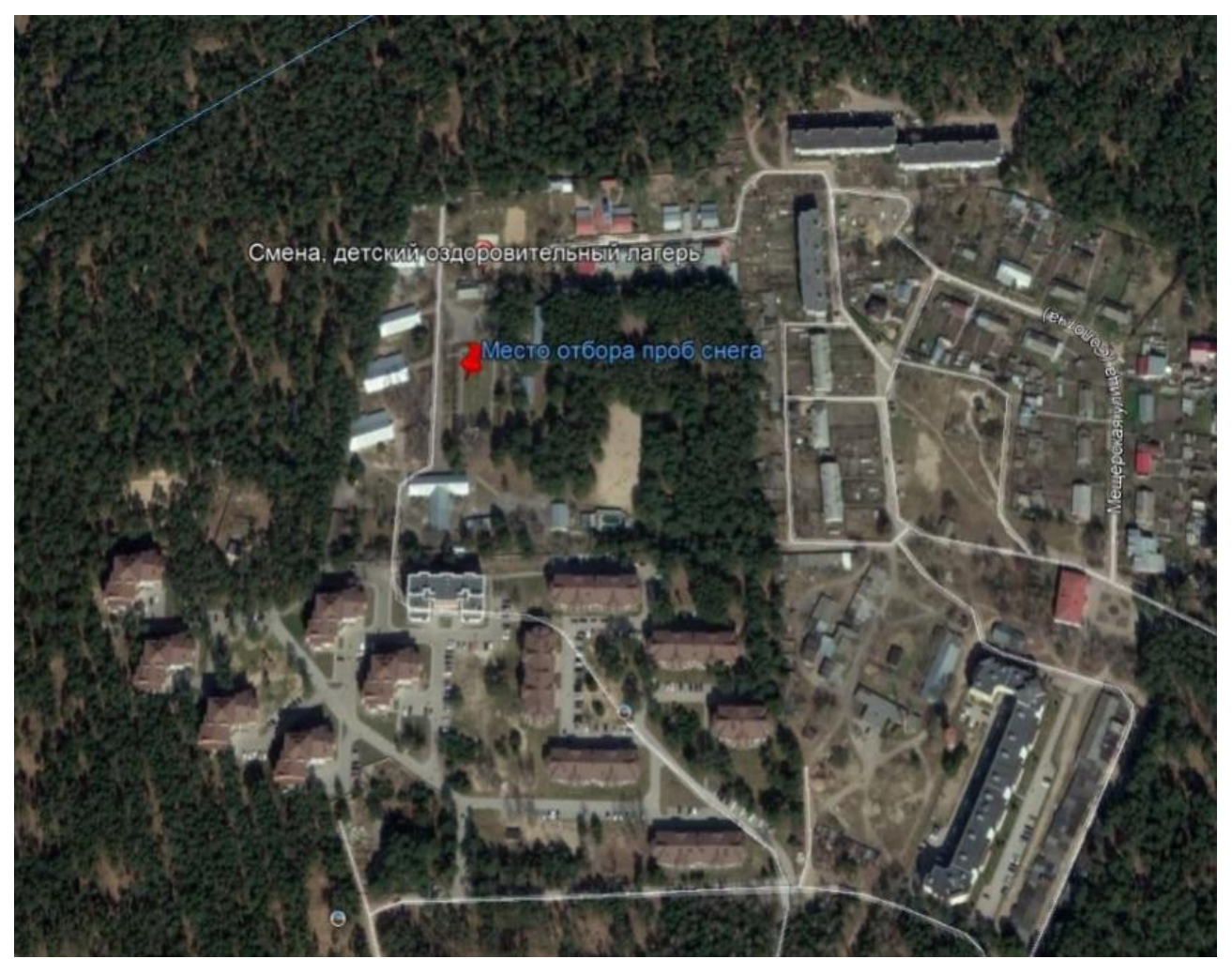

Рисунок 1. Схема расположения стаџионарного участка проведения снегомерной съемки на землях лесного массива п. Солотча

Обобщенные результаты многолетних наблюдений за снежным покровом и снегомерной съемки, а также расчета запаса воды в снеге на

осушенных землях лесного массива п. Солотча представлены в таблице 1 и на рисунке 2.

Таблица 1

Результаты многолетней снегомерной съемки на землях лесного массива п. Солотча Рязанской области

\begin{tabular}{|c|c|c|c|}
\hline Годы & $\begin{array}{c}\text { Мощность снежного } \\
\text { покрова }\left(h_{\mathrm{cp}}\right), \mathrm{cm}\end{array}$ & $\begin{array}{c}\text { Плотность снежного } \\
\text { покрова }\left(d_{\mathrm{cp}}\right), \Gamma / \mathrm{cm}^{3}\end{array}$ & $\begin{array}{c}\text { Запас воды в снеге }\left(Q_{\mathrm{cp}}\right), \\
\text { мм }\end{array}$ \\
\hline 2012 & 28 & 0,28 & 78,4 \\
\hline 2013 & 32 & 0,31 & 99,2 \\
\hline 2014 & 34 & 0,30 & 102,0 \\
\hline 2019 & 16 & 0,21 & 109,0 \\
\hline 2020 & 10 & 0,27 & 31,5 \\
\hline Среднее & 24,0 & 0,27 & 84,0 \\
\hline
\end{tabular}

Многолетние натурные исследования, выполненные на стационарном участке, показали, что наибольшая мощность снежного покрова наблюдалась в 2014 году - отклонение от среднего значения составило $42 \%$, наименьшая же мощность снежного покрова наблюдалась в 2020 году - отклонение от среднего значения составило $42 \%$. 


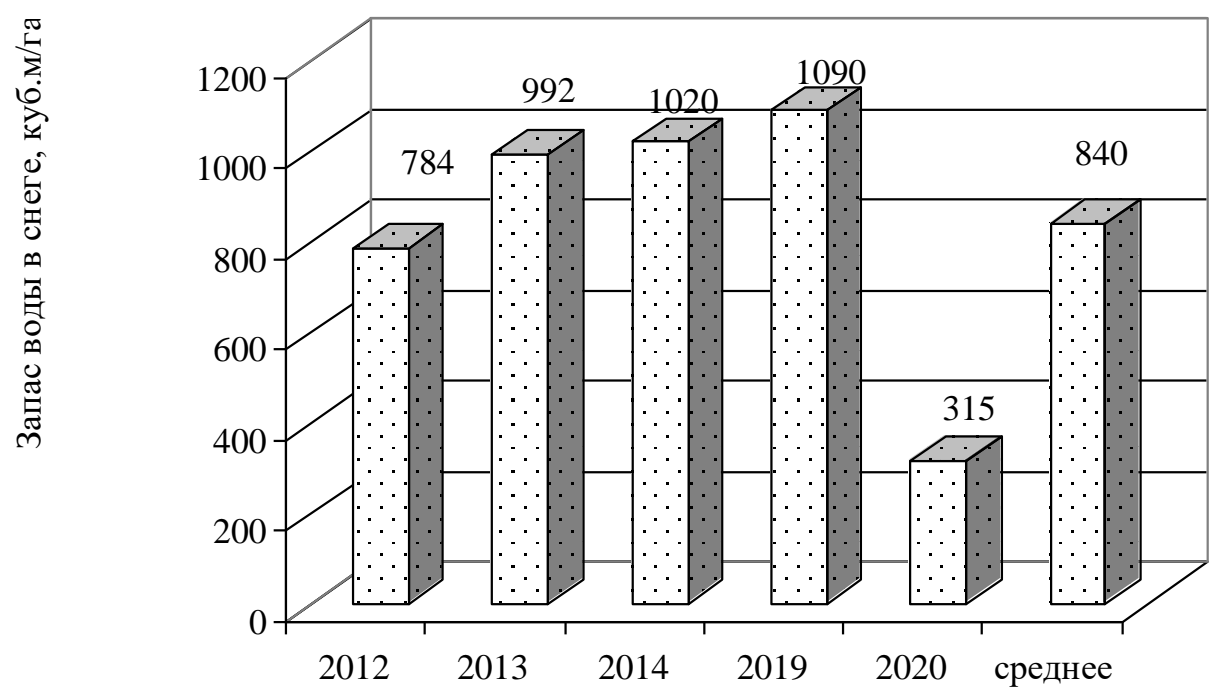

Рисунок 2. Многолетняя динамика запасов воды в снежном покрове лесного массива n. Солотча Рязанской области

В ходе многолетнего изучения плотности снежного покрова было установлено, что в 2019 году она была наименьшей, отклонение от среднего значения составило -22 \%. Наибольшее значение плотности снежного покрова было зафиксировано в 2013 году, когда отклонение от среднего значения составило $15 \%$.

Как видно из таблицы 1, увеличение мощности и плотности снежного покрова оказывают благоприятное влияние на увеличение запасов воды в снеге. Изучение многолетней динамики запасов воды в снежном покрове лесного массива п. Солотча показало, что за период 2013-2014 гг. и 2019 год происходило увеличение запасов воды в снеге от $18 \%$ в 2013 году, до 30 \% в 2019 году. На 2020 год пришлись наименьшие запасы воды в снеге: разница составила $-63 \%$ от среднего значения.

Таким образом, в условиях аномально теплой зимы, ранней весны, минимальных запасах воды в снеге и дефиците весенних атмосферных осадков, в период весенних полевых работ 2020 года сельскохозяйственным предприятиям необходимо уделять особе внимание своевременному проведению мероприятий по ранневесеннему сохранению влаги в корнеобитаемом слое почвы, например, оперативно проводить работы по боронованию зяби.

\section{Список литературы}

1. Виноградов Д.В., Ильинский А.В., Данчеев Д.В. Экологические аспекты охраны окружающей среды и рационального природопользования: учебное // Рязань: ФГБОУ ВО РГАТУ, 2017. - 128 c.

2. Виноградов Д.В., Ильинский А.В., Данчеев Д.В. Экология агрэкосистем. - Рязань: ИП Жуков В.Ю., 2020. -256 c.

3. Евсенкин К.Н., Ильинский А.В. Изучение запасов воды в снежном покрове мелиорированных земель // Экологическое состояние природной среды и научно-практические аспекты современных агротехнологий : материалы III междунар. науч.-практ. конф. (Рязань, ФГБОУ ВО РГАТУ, 18 апреля 2019) . - Рязань : ИП Жуков B.Ю., 2019. - C. 124-127.

4. Евсенкин К.Н., Ильинский А.В. Результаты изучения запасов воды в снежном покрове на землях Рязанской Мещеры // Евразийский Союз Ученых (ЕСУ). Ежемесячный научный журнал. 2 часть. - 2019. - 11 (68). - С. 33-35.

5. Захарова О.А., Евсенкин К.Н. Характеристика грунтовых вод на мелиорированном агроландшафте // Вестник Рязанского государственного агротехнологического университета им. П.А. Костычева. - 2016. - № 2 (30). - С. 18-22.

6. Ильинский А.В., Игнатенок В.А. Результаты мониторинга сбросных и коллекторно-дренажных вод длительно используемых осушенных земель на примере мелиоративной системы «Тинки-2» Рязанской области // Проблемы рационального использования природохозяйственных комплексов засушливых территорий сб. науч. тр. науч. Ред. Зволинский В.П. - ФГБНУ «ПНИИАЗ», 2015. - С. 74-77.

7. Ильинский А.В., Виноградов Д.В., Данчеев Д.В. Экологические основы природопользования: учебное пособие // Рязань: ФГБОУ ВО РГАТУ, 2017. - $128 \mathrm{c}$.

8. Ильинский А.В., Виноградов Д.В, Гогмачадзе Г.Д. Экологическое обоснование способа агрохимической мелиорации почв в условиях техногенеза // АгроЭкоИнфо. - 2018, №1.

http://agroecoinfo.narod.ru/journal/STATYI/2018/1/st -123.doc.

9. Ильинский А.В., Евсенкин К.Н. Экспериментальные данные по запасам воды в снежном покрове мелиорированных // Научнометодическое обеспечение развития мелиоративно- 
водохозяйственного комплекса. Сборник научных трудов. М.: Изд. ВНИИГиМ, 2020. - С.84-88.

10. Методические указания по проведению наблюдений за мелиоративным состоянием осушенных земель. - Л.: СевНИИГиМ, 1972. - 155 c.

11. Никитин И.С., Плехов Л.Н., Томин Ю.А. Определение испарения со снежного покрова // Мелиорация земель Мещерской низменности. Рязань: Мещерская 3ОМС, 1974. - С. 21-25.
12. Чеботарев А.И. Гидрологический словарь. - Л.: Гидрометеорологическое издательство, 1964. $-224 \mathrm{c}$.

13. Шатилов И.С. Химический состав атмосферных осадков // Вестник сельскохозяйственной науки. - 1990. - № 5. - С. 4042 .

14. Шумаков Б.Б. Научные основы ресурсосбережения и охраны природы в мелиорации и водном хозяйстве. - М.: НР, 1998. $312 \mathrm{c}$.

\title{
К ВОПРОСУ ПРИМЕНЕНИЯ НА ДЕГРАДИРОВАННЫХ ЧЕРНОЗЕМАХ МИКРОЭЛЕМЕНТНЫХ ДОБАВОК В СОСТАВЕ ПРИЕМОВ АГРОХИМИЧЕСКОЙ МЕЛИОРАЦИИ
}

DOI: 10.31618/ESU.2413-9335.2020.5.73.678

Ильинский Андрей Валерьевич кандидат с/х наук, доцент,

ФГБНУ «ВНИИГиМ им. А.Н. Костякова»,

Москва

\section{ON THE ISSUE OF APPLICATION OF MICROELEMENT ADDITIVES IN THE COMPOSITION OF AGROCHEMICAL RECLAMATION TECHNIQUES ON DEGRADED CHERNOZEMS}

\author{
Ilinskiy Andrey \\ candidate of agricultural sciences, associate professor \\ Federal State Scientific Institution \\ «All-Russian research institute for hydraulic engineering \\ and reclamation of A.N. Kostyakov», \\ Moscow
}

\section{АННОТАЦИЯ}

Особенности почвообразования и специфика элементного состава материнской породы оподзоленных и выщелоченных черноземов Рязанского региона предопределили специфику содержания микроэлементов в пахотном слое почвы. Например, содержание таких важных для сельскохозяйственных культур микроэлементов как молибден и марганец ниже критерия глобальной оценки «почвы мира». Данные микроэлементы участвуют в обмене веществ и ферментативных реакциях, их нехватка приводит как к снижению урожайности сельскохозяйственных культур, так и к ухудшению качества растениеводческой продукции. Исправить подобную ситуацию возможно путем использования микроэлементных добавок при разработке комплексных приемов агрохимической мелиорации деградированных черноземов.

\section{ABSTRACT}

Features of soil formation and the specific element composition of the parent rock of podzolized and leached chernozems of the Ryazan region predetermined the specifics of the content of trace elements in the arable soil layer. For example, the content of such important microelements for agricultural crops as molybdenum and manganese is lower than the criteria for the global assessment of the "soil of the world". These microelements are involved in metabolism and enzymatic reactions, their lack leads to both a decrease in crop yields and a deterioration in the quality of crop products. It is possible to correct this situation by using trace element additives in the development of complex methods of agrochemical reclamation of degraded chernozems.

Ключевые слова: мелиорация; микроэлементы; оподзоленные и выщелоченные черноземы; почва; почвообразующая порода; растения; сельское хозяйство; тяжелые металлы; удобрение; экологическая безопасность.

Keywords: reclamation; trace elements; podzolized and leached chernozems; soil; soil-forming rock; plants; agriculture; heavy metals; fertilizer; environmental safety.

Выщелоченные и оподзоленные черноземы являются наиболее плодородными почвами Рязанской области, они широко распространены в южной и центральной частях области среди темносерых лесных почв (Елецкий и Мичуринский природно-почвенные округа), занимают около 800 тыс. га пашни [1]. Черноземы, по сравнению с другими почвами, характеризуются более высоким естественным плодородием. Содержание гумуса в черноземах Рязанской области колеблется от 4 до $7 \%$, реакция почвенного раствора (РН) варьирует от 4,5 - 6,0, степень насыщенности основаниями 85 $90 \%$, сумма обменных оснований $46-50$ мг-экв/100 г., емкость поглощения катионов 20 - 50 мг-экв/100 г., частицы менее 0,01 мм составляют 39 \% [8]. 